Eva Schmidova - Premysl Hojka - Bohumil Culek - Filip Klejch - Michal Schmid*

\title{
DYNAMIC STRENGTH AND ANISOTROPY OF DMLS MANUFACTURED MARAGING STEEL
}

This paper deals with maraging steel, as a prospective material for the 3D printed lightened structural parts of transport means. Direct Metal Laser Sintering technology was tested for creation of a thin-wall structure with defined internal geometry. The referential samples prepared by the DMLS technology were examined under quasi-static and high strain rate loading using a servo-hydraulic testing machine at strain rates up to $1400 \mathrm{~s}-1$. Microstructural analyses served for evaluation of structural homogeneity and metallurgy quality, including the influence of crystallization gradient. The stabile ductile fracture mode was proven by fractography analyses, even at a maximal strain rate. The post-impact tests were conducted to evaluate the local residual plasticity by indentation tests.

Keywords: DMLS technology, 3D printing, maraging steel, impact tensile tests

\section{Introduction}

Additive manufacturing (AM), as the industrial version of the 3D-printing, is already used mainly for plastic prototypes. It works directly with graphic models, so designers can devise new shapes without regards for existing manufacturing limitations. However, its application to critical metal alloy parts is still a significant milestone for the technology. It is necessary to explore how to use additive manufacturing with a wider range of metal alloys, how to combine different alloys for functional graded materials, and so on [1].

Another promising research focus is fabrication and study of the lightweight designs based on complex internal designs - from the micro- up to the macro-scale. The direct laser writing system provides a basis for fabrication of the controlled 3D micro-trusses. While the micro-production process enables the high-resolution structuring of arbitrary 3D patterns mainly determined by the laser spot size [2], the macro-scale is typified by regular internal geometry. Majority of studies regarding the high strain rate loading of cellular foam cores are predominantly limited to metallic foam cores, such as aluminum [3-4].

The additive manufacturing approach is used both for rapid prototyping, as it decreases development time for new products and production manufacturing, to simplify assemblies and complex geometries. The range of currently available metal materials for the 3D printing ranges from titanium alloys and nickel alloys to the high-grade stainless steels, and this range is expanding rapidly together with increases in quality requirements.

The Direct Metal Laser Sintering (DMLS) and electron beam melting are the main representative processes of the powderbased fusion technologies. The DMLS uses uncoated pre-alloyed metal powders as the sintering material [5]. It is a laser-based rapid prototyping and tooling process by means of which the net-shaped parts are fabricated in a single process. Complex parts can be produced directly from the 3D CAD models by layer-wise solidification of metal powder layers in portions of the layer corresponding to the cross section of the 3D part in the respective layer [6]. It needs to be pointed out that only very limited information about serial production and usage of complex parts exists.

The presented experimental study of maraging steel is focused on dynamic fracture behaviour using samples 3D printed by the DMLS technology. The obtained results will serve for internal geometry design of lightweight high-performance products. The main macro- and microstructural parameters, together with mechanical responses at defined geometrical and loading conditions, are necessary for precise numerical simulation of products with complex internal geometries.

\section{Material and methods}

The experimental analyses were focused on:

- evaluation of dynamic hardening capacity under different strain rates and

- study of internal phase and structural conditions including metallurgical quality.

The defined samples geometry prepared by the DMLS technology is documented in Figure 1, printing direction is indicated by arrow. Direct measurement by strain gauges was considered necessary for the precise measurement of dynamic responses; the crucial requirement is to suppress the dynamic response of the loading and clamping system in the case of increased strain rate and complex sample shapes.

The static stress-strain response was evaluated by the standard tensile test using a ZWICK/ROEL Z-030 machine and the dynamic behaviour was tested using an AH 40-100 M062 electro-hydraulic system with Inova TestControl control system at two loading rates $-5 \mathrm{~m} / \mathrm{s}$ and $10 \mathrm{~m} / \mathrm{s}$.

The maraging steels are generally characterized by a high nickel content, very low carbon content and use of the substitutional elements or precipitates to produce the

\footnotetext{
* Eva Schmidova, Premysl Hojka, Bohumil Culek, Filip Klejch, Michal Schmid Faculty of Transport Engineering, University of Pardubice, Czech Republic E-mail: eva.schmidova@upce.cz
} 

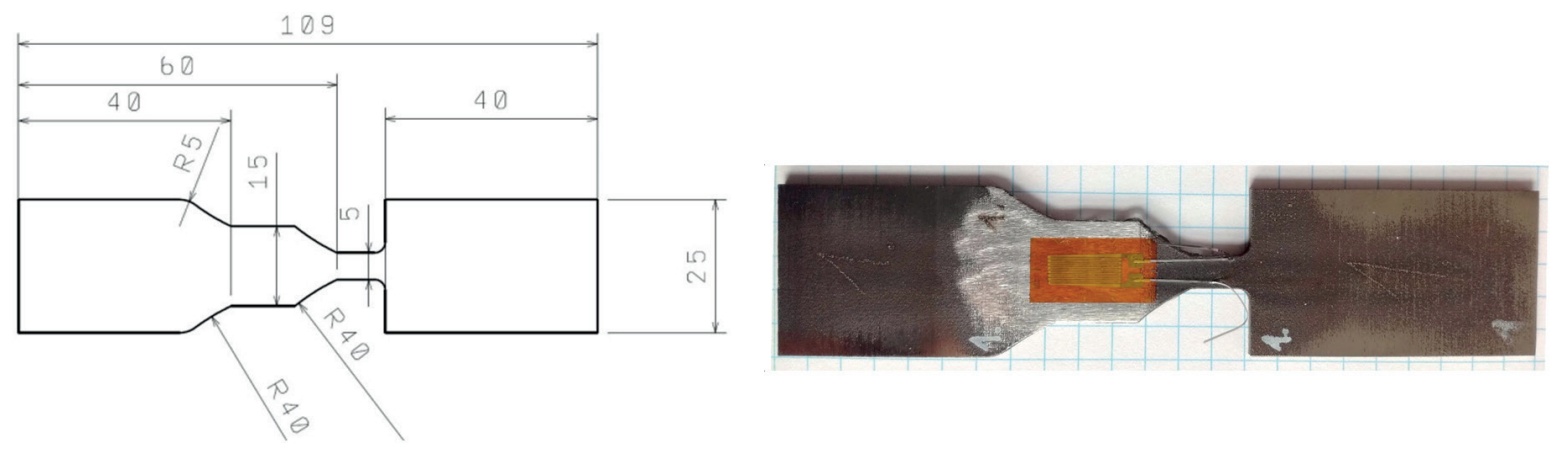

Figure 1 Samples geometry

Table 1 Chemical composition of the tested steel [wt. \%]

\begin{tabular}{|c|c|c|c|c|c|c|c|c|c|c|c|}
\hline & $\mathrm{C}$ & $\mathrm{Si}$ & $\mathrm{Mn}$ & $\mathrm{P}$ & $S$ & $\mathrm{Cr}$ & Mo & $\mathrm{Ni}$ & $\mathrm{Co}$ & $\mathrm{Ti}$ & $\mathrm{Al}$ \\
\hline \multirow[t]{2}{*}{ MS1 } & $\leq 0.03$ & $\leq 0.1$ & $\leq 0.1$ & $\leq 0.01$ & $\leq 0.01$ & $\leq 0.5$ & 4.5 & 17.0 & 8.5 & 0.6 & 0.05 \\
\hline & & & & & & & 5.2 & 19.0 & 9.5 & 0.8 & 0.15 \\
\hline \multirow[t]{2}{*}{1.2709} & $\leq 0.03$ & $\leq 0.1$ & $\leq 0.15$ & $\leq 0.01$ & $\leq 0.01$ & $\leq 0.25$ & 4.5 & 17.0 & 8.5 & 0.8 & - \\
\hline & & & & & & & 5.2 & 19.0 & 10 & 1.2 & \\
\hline
\end{tabular}

age hardening. The material used - Maraging Steel MS1 - is a steel powder, which has been optimised especially for the 3D processing; it is a martensite-hardenable steel corresponding to 1.2709 (X3NiCoMoTi 18-9-5). The chemical composition, in comparison to conventional maraging steel is given in Table 1. This kind of steel is characterised by excellent strength combined with high toughness; in the $3 \mathrm{D}$ printed form it is intended for high-load tools. The parts are easily machinable after the building process and can be easily post-hardened to more than $50 \mathrm{HRC}$ by age-hardening at $490{ }^{\circ} \mathrm{C}\left(914^{\circ} \mathrm{F}\right)$ for 6 hours. They also have excellent weldability and polishability. The tested samples were in the primary stage - without the post-hardening, to find out influence of the used technology including the natural surface relief.

The fractography analyses served for the fracture mode identification. Impurities were identified using the energy dispersive X-ray spectroscopy.

The local mechanical heterogeneity, due to direction of the layer cladding, together with the plastic flow at maximal strain rate, were evaluated by specific indentation test, using the cylindrical indenter and Hencky theory of plasticity.

\section{Results and discussion}

\subsection{Microstructural characterisation}

The resulting DMLS 3D printed parts have different material structures and therefore different mechanical properties than parts obtained through the conventional techniques, depending upon the materials. Due to the layer-wise building method, the parts have a certain anisotropy. Figure 2 illustrates the perpendicular versus longitudinal features in a macroscopic view. Visible are the effects of a layer-by-layer build process, which can be reduced or removed by appropriate heat treatment.
Especially for metal powder, there are some specific problems of the DMLS technology related to powder quality: particle size distribution, morphology, internal porosity, chemical composition, roughness. Due to this, the internal continuity and prospective presence of imperfections along the layers interphase were checked. No effects of process instabilities were observed as defective filling of layers, porosity in final parts, or lack of fusion defects.

The powder is generally discussed as one of the major costs (and problems) contributing to the additive manufacturing process. It is useful for technology optimization to distinguish each source of obtained product quality. The observed microimpurities were identified by the energy chemical microanalysis mainly as TiN ( $\mathrm{TiCN}$ ), without substantial influence on the fracture response.

The basic principle of the DMLS technology is to melt down very thin layers $(20-60 \mu \mathrm{m})$ of metal powder with an electronically driven laser beam. A layer of metal powder with the grain size fractions below $6 \mu \mathrm{m}$ is spread on a steel base plate. It is possible to build complex geometries, even those that are impossible to obtain with any other kind of technology, with accuracy up to $\pm 0.05 \mathrm{~mm}$ [7]. The SEM image in Figure 3 shows the typical microstructure in the longitudinal direction. A very fine cellular microstructure without typical martensitic morphology was documented in the natural stage of the printed steel. Epitaxial crystallisation at the grains bound together with chemical heterogeneity is the typical result of a very high cooling rate.

The present microstructure is mainly influenced by the energy deposition, which depends on the beam diameter and the raster speed. In addition, the re-melt strategy will selectively and often systematically alter the microstructure and therefore the residual product properties. The product volume (or size) will also influence the thermal issues, primarily cooling or rate of cooling, which can also have a significant effect on the microstructure. 


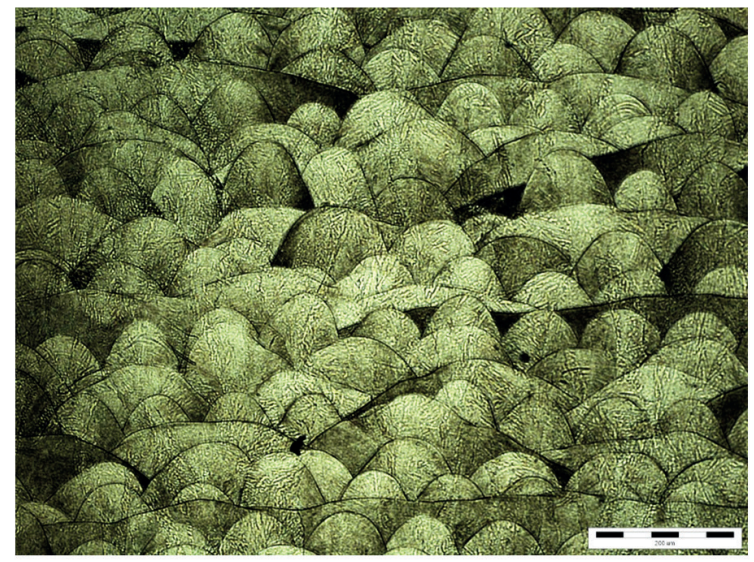

a) Horizontal (XY) direction

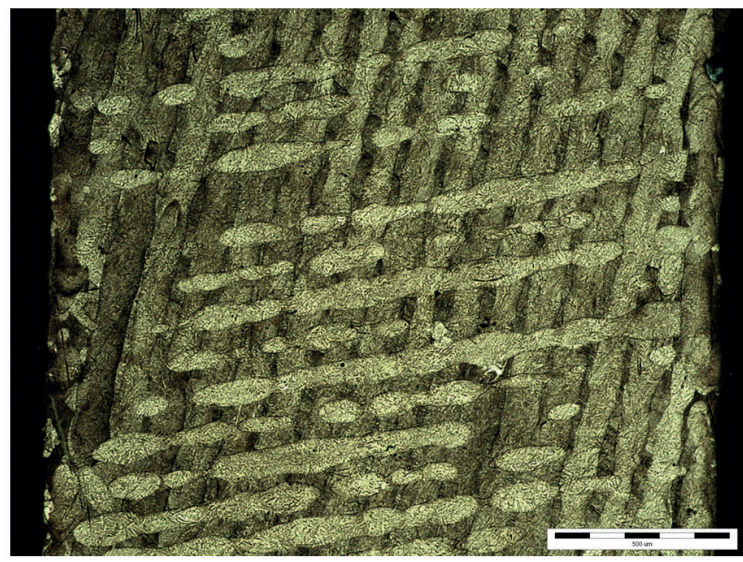

b) Vertical direction $(Z)$

Figure 2 Macro-structure of printed layers

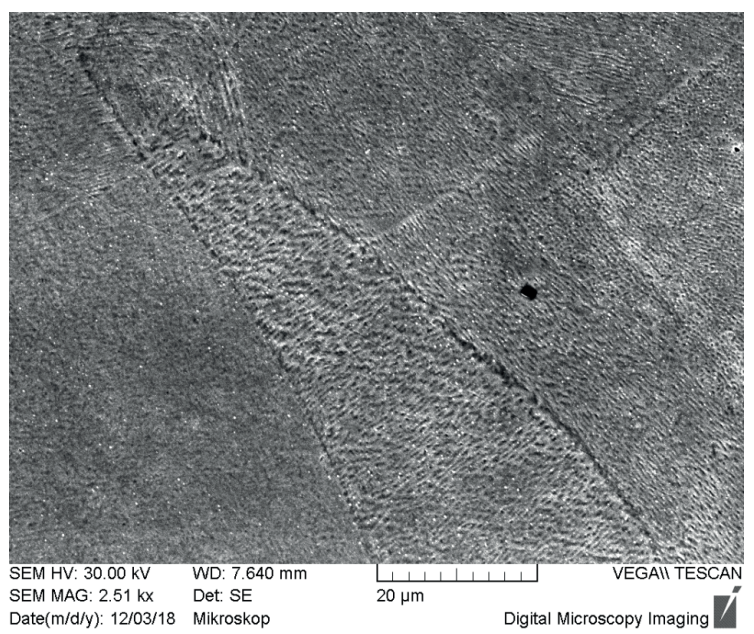

Figure 3 Typical microstructure in the longitudinal direction

Different thermal boundaries are acting during the build-up process (by heating up or cooling down) of the single layers.

\subsection{Static and dynamic fracture behaviour}

The maraging steels are typical by capacity to an ultimate tensile strength of $1500 \mathrm{MPa}$ or greater, in the form of sheet, with a wall or plate thickness equal to or less than $5 \mathrm{~mm}$. The tensile strength of the maraging Steel MS1 in vertical direction, without the age hardening, typically reaches $1100 \mathrm{MPa}$, yield strength $1000 \mathrm{MPa}$ [8-10]. Performed static test in the vertical direction confirmed this capacity; the same orientation of the uniaxial loading was used for dynamic fracture tests.

The tested 3D process resulted in dynamic behaviour, reflected in the stress/strain records in Figure 4. Applied average strain rates $\left(3 \mathrm{~s}^{-1}, 700 \mathrm{~s}^{-1}, 1400 \mathrm{~s}^{-1}\right)$ revealed a significant dynamic hardening capacity. An almost $25 \%$ increase of UTS at strain rate $700 \mathrm{~s}^{-1}$ and $38 \%$ at strain rate $1400 \mathrm{~s}^{-1}$ was measured compared to standard static strength, using 3 samples for each loading regime.

The aforementioned strengthening effect has proven the presence of a dislocation hardening process. The performed fractography analysis confirmed the ductile fracture mode (Figure 5 ), even at the maximal loading rate. The local presence of

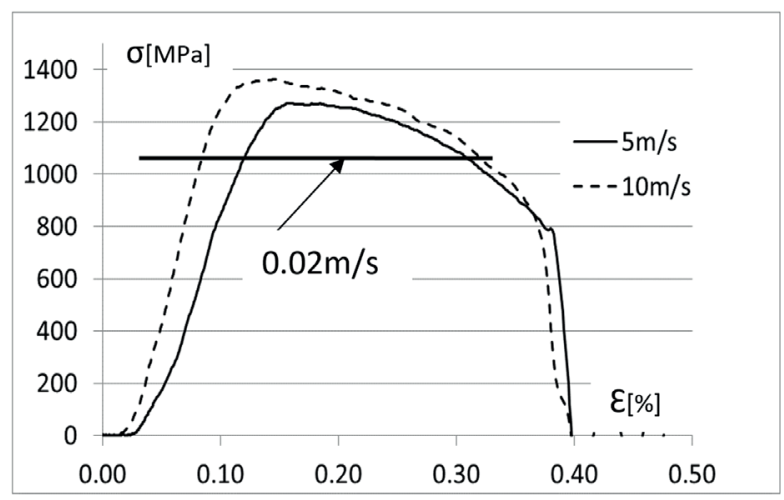

Figure 4 Dynamic records after the uniaxial loading

impurities did not lead to a change in the fracture mode. This fracture behaviour is very promising from the point of resistance to internal defects at impact loading.

The main generally considered shortcoming of the 3D printed maraging steel is a mechanical anisotropy. Heterogeneous residual stress distribution due to intensive temperature gradient, contributes to an oriented microstructure influence. The comparative indentation test was used for evaluation of elastoplastic capacity in vertical vs. horizontal direction (Table 2).

Measured relaxation coefficient, as the ratio of elastic and the total energy consumption using the Wickers indenter $\left(\eta=\left(\mathrm{W}_{\text {elast }} /\right.\right.$ $\left.\left.\mathrm{W}_{\text {total }}\right) \cdot 100[\%]\right)$ ) reflects the residual plastic capacity. Comparative yield stress (CYS) $\left[\mathrm{N} / \mathrm{mm}^{2}\right]$, was determined by a cylindrical indenter $0.5 \mathrm{~mm}$ in diameter. According to hypothesis about behavior of material during the extrusion of a cylindrical indenter [11], the shear yield stress was determined by defined ratio to the Equivalent Yield Force at the elastic limit of material response (Figure 6). An important parameter of dynamic material response is residual strengthening. Therefore, in order to fully understand the impact response of the tested high strength steel, an extension of deformation and strengthening has been considered. Effect of dynamic deformation at strain rate $1400 \mathrm{~s}^{-1}$ is reflected by the same indentation parameters in Table 2. 


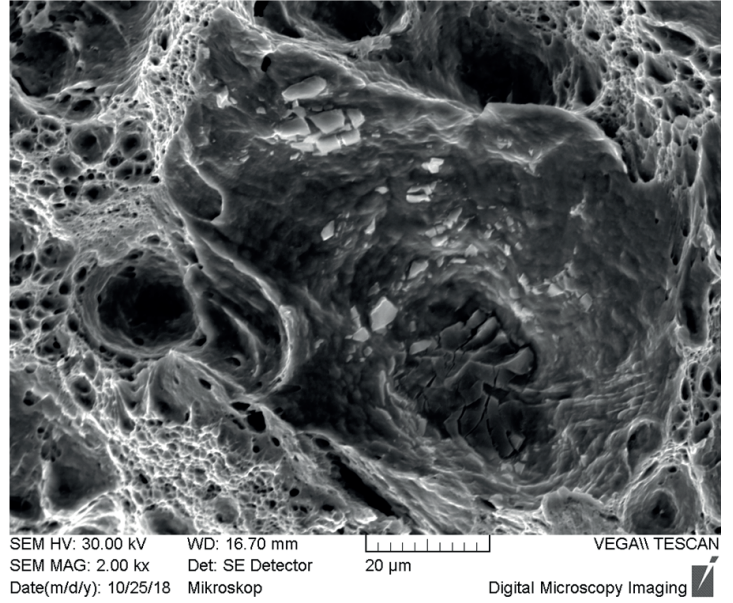

(a) $0.02 \mathrm{~m} / \mathrm{s}$

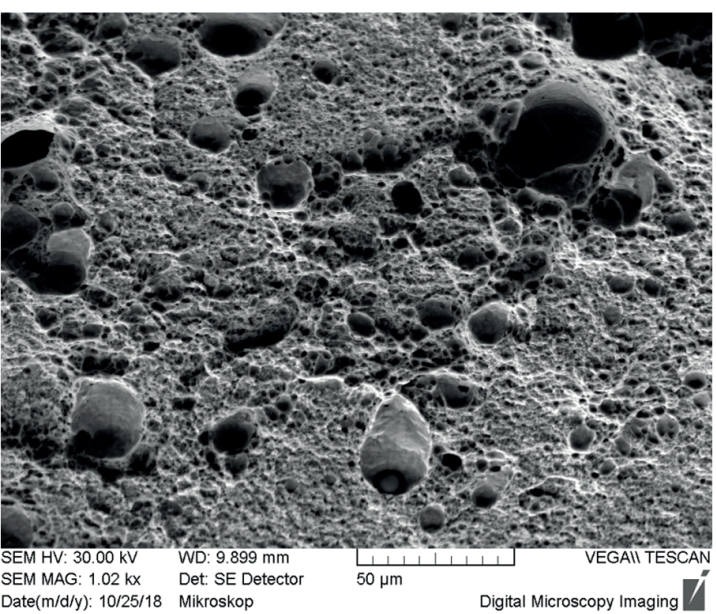

(b) $5 \mathrm{~m} / \mathrm{s}$

Figure 5 Fracture morphology of the printed maraging steel

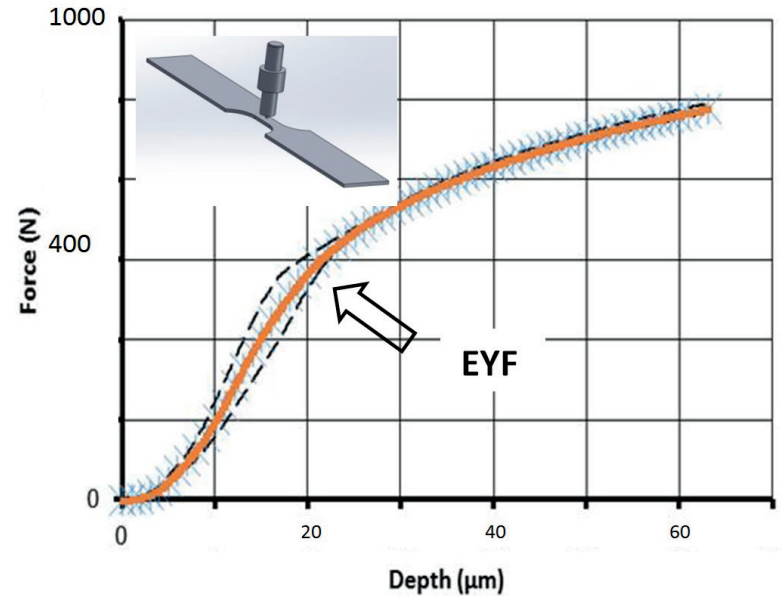

Figure 6 Indentation curve evaluation

Table 2 Mechanical anisotropy measured by indentation test

\begin{tabular}{ccccc}
\hline & $\begin{array}{c}\text { relaxation coefficient } \\
\eta[\%]\end{array}$ & $\begin{array}{c}\text { Equivalent Yield } \\
\text { Force EYF [N] }\end{array}$ & $\begin{array}{c}\text { Equivalent Yield } \\
\text { Displacement }[\mu \mathrm{m}]\end{array}$ & $\begin{array}{c}\text { Comparative yield stress } \\
\text { CYS [MPa] }\end{array}$ \\
\hline $\begin{array}{c}\sigma_{\mathrm{y}} \\
\text { vertical }\end{array}$ & $36 \pm 1.4$ & $462 \pm 2.3$ & $18.48 \pm 1.9$ & $2354 \pm 12$ \\
horizontal & $29 \pm 2.0$ & $412 \pm 19$ & $19.37 \pm 2.9$ & $2099 \pm 98$ \\
$\begin{array}{c}\text { horizontal } \\
\text { hardened }\end{array}$ & 43 & 454 & 23.07 & 2314 \\
\hline
\end{tabular}

* after dynamic hardening, i.e. close to dynamic fracture at $10 \mathrm{~m} / \mathrm{s}$

\section{Conclusions}

The AM is still a young technology and it exhibits a number of process problems that need to be understood when developing a part to be produced by the AM, especially by the DMLS. The main process problems are connected with the primary quality of powder and very complex technology requirements. When using the additive manufacturing, several boundary conditions are changed compared to traditional designs and processes. Different technological parameters need to be considered for the lightweight structure topology optimisation, many factors can alter the mechanical properties of the printed steel.
Material structures differ from casting/forging; thanks to the very fine microstructure of the tested maraging steel, high static and also dynamic strength values were obtained even in their natural stage. Significant strengthening effect was proven at different strain rates, without a tendency to change the primary ductile fracture mode.

The used technology parameters led to a high-quality inner structure with negligible influences of metallurgical defects.

A restrictive factor could be the surface roughness driven by the deposition layer thickness, mainly in connection with the fatigue strength. When considering the aim of forming lightweight structures with complex inner designs, the roughness is internal and external, which could influence the flow behaviour of internal 
channels. The design of internal geometry has to avoid large thermal stresses.

Considerable plastic anisotropy has been confirmed in the as-built condition by indentation tests. Anisotropy can be reduced by aging heat-treatment of maraging steel. However, as was verified in some experimental studies [8], a degree of transverse strain anisotropy is likely to remain due to the AM alloy's fabrication history for the MS1 material. With use of the comprehensive material analyses, considering the constructed contour of printed geometry, the final mechanical response can be tailored to meet the desired design requirements for the part production purposes.

\section{Acknowledgement}

This article was made thanks to the support from project FV30149.

\section{References}

[1] BUCHANAN, C., GARDNER, L. Metal 3D printing in construction: A review of methods, research, applications, opportunities and challenges. Engineering Structures [online]. 2019, 180, p. 332-348. ISSN 0141-0296, eISSN 1873-7323. Available from: https://doi.org/10.1016/j.engstruct.2018.11.045

[2] MURR, L. E., JOHNSON, W. L. 3D metal droplet printing development and advanced materials additive manufacturing. Journal of Materials Research and Technology [online]. 2017, 6(1), p. 77-89. ISSN 2238-7854. Available from: https://doi.org/10.1016/j.jmrt.2016.11.002

[3] THOMAS, T., MAHFUZ, H., CARLSSON, L.A., KANNY, K., JEELANI, S. Dynamic compression of cellular cores: temperature and strain rate effects. Composite Structures [online]. 2002, 58(4), p. 505-512. ISSN 0263-8223, eISSN 1879-1085. Available from: https://doi.org/10.1016/S0263-8223(02)00159-9

[4] DANNEMANN, K. A., LANKFORD, J. High strain rate compression of closed-cell aluminum foam. Materials Science and Engineering: $A$ [online]. 2000, 293(1-2), p. 157-64. ISSN 0921-5093. Available from: https://doi.org/10.1016/S0921-5093(00)01219-3

[5] DUDA, T., RAGHAVAN, L. V. 3D metal printing technology. IFAC-PapersOnLine [online]. 2016, 49(29), 2016, p. 103-110. ISSN 2405-8963. Available from: https://doi.org/10.1016/j.ifacol.2016.11.111

[6] BhaVAR, V., KATTIRE, P., PATIL, V., KHOT, S., GUJAR, K. SiNGH, R. A Review on powder bed fusion technology of metal additive manufacturing. 4th International Conference and Exhibition on Additive Manufacturing Technologies AM 2014: proceedings. Additive Manufacturing Society of India (AMSI), 2014.

[7] SUREL, A. Direct metal laser-sintering (DMLS). Avec l'EOSINT M 270. Eighteenth International Conference \& Exhibition Moulding 2008 : proceedings. 2008.

[8] MOONEY, B., KOUROUSIS, K. I., RAGHAVENDRA, R. Plastic anisotropy of additively manufactured maraging steel: influence of the build orientation and heat treatments. Additive Manufacturing [online]. 2019, 25, p. 19-31. ISSN 2214-8604, eISSN $2214-7810$. Available from: https://doi.org/10.1016/j.addma.2018.10.032

[9] SUN, Y., LI, Q. M. Dynamic compressive behavior of cellular materials: A review of phenomenon, mechanism and modelling. International Journal of Impact Engineering [online]. 2018, 12, p. 74-115. ISSN 0734-743X. Available from: https://doi.org/10.1016/j.ijimpeng.2017.10.006

[10] SHA, W., GUO, Z. Maraging steels, modelling of microstructure, properties and applications, Cambridge UK: Woodhead Publishing, 2009. ISBN 978-1-84569-686-3.

[11] BOWMAN, K. J. Mechanical behavior of materials. Hoboken, NJ: John Wiley, 2004. ISBN 978-0-471-24198-0. 